\title{
THE
}

\section{STUPIDITY OF WAR}

AMERICAN FOREIGN POLICY AND THE CASE FOR COMPLACENCY JOHN MUELLER

"A characteristically bold and sweeping assault on the key tenets of American national security policy. Even readers who do not agree will be challenged by a well-crafted and thoroughly documented argument."

Martha Crenshaw, Stanford University \& Wesleyan University
JOHN MUELLER

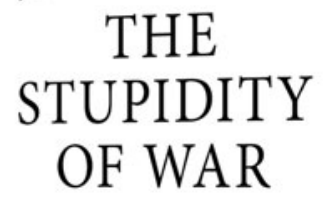

AMERICAN FOREIGN POLICY AND THE CASE FOR COMPLACENCY

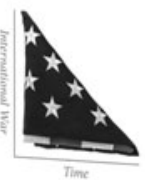

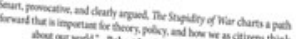

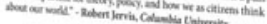

"Unfailingly incisive, witty, original, prescient, and constructively contrarian. True to form, this case for complacency will shake you out of your complacency on American military policy."

Steven Pinker, Harvard University

FOLLOW US ON SOCIAL MEDIA

๑ CambridgeUniversityPressPolitics

(2) Cup_Polisci (a) cupacademic
国圈 CAMBRIDGE

UNIVERSITY PRESS 


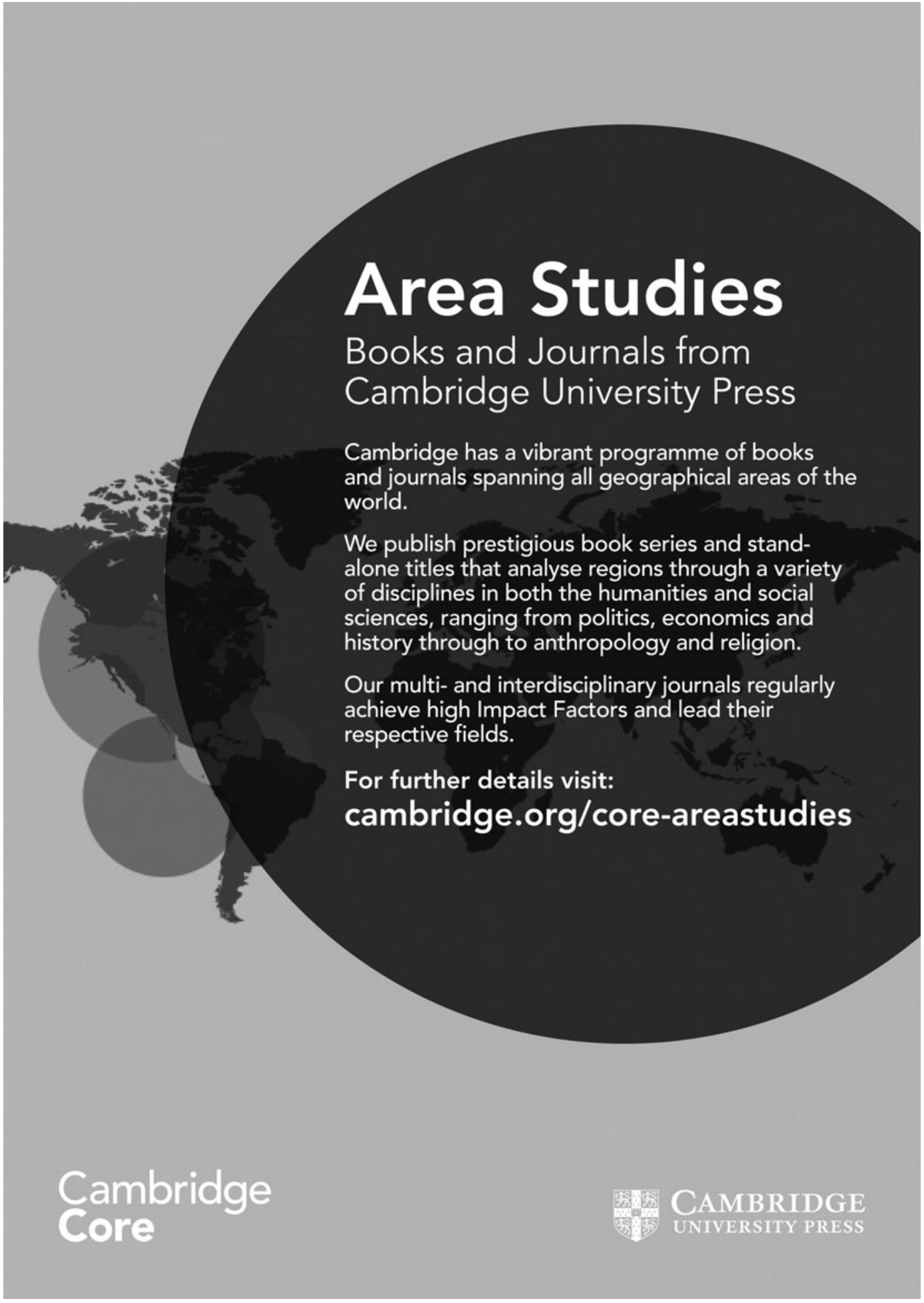




\section{Instructions for contributors}

\section{Editorial policy}

Journal of American Studies publishes works by scholars from all over the world on American literatures, history, politics, foreign relations, philosophy, art history, visual culture, economics, film, popular culture, geography, material culture and related subjects. We also welcome research topics covering fields related to American Studies and which include (in alphabetical order): African American Studies; African Diasporic Studies; America in the World Studies; Asian American Studies; Chicana/o and Latina/o Studies; Chinese American Studies; Cultural Studies; Globalisation Studies; Indigenous Studies; Hemispheric Studies; Slavery Studies; Transatlantic Studies; Transnational Studies. A Notes and Comments section provides a forum for shorter pieces and responses from readers to points made in articles, reviews, states of the field/thought pieces/review essays/ roundtable contributions. We are also keen to consider contributions that go beyond the normal confines of an academic article — whether these be Research Notes, States of the Field pieces, Thought Pieces, Forums and Roundtable Discussions, Exhibition Commentaries, Research Notes. Proposals on this front should be emailed directly to the editors.

Journal of American Studies welcomes proposals for special issues or special collections of essays within an issue. Proposing editors should initially submit a synopsis of a minimum of 1500 words detailing the academic significance of the collection, and 200 words abstracts of each of the essays as well as a one line contributor biography. These will be considered by the JAS Editorial Team and the journal's Editorial Board and then sent to readers for feedback. If the proposal passes the initial stage, JAS will then invite full essays, to be read and reviewed using our standard process for submissions.

For more information, please contact the Co-Editors: Dr. Sinéad Moynihan and Dr. Nick Witham (full contact information provided below).

\section{Book reviews}

Editorial correspondence relating to book reviews should be sent to the following email address: jasreviews@leicester. ac.uk

\section{Submissions}

Papers should be submitted online via the following website at: mc.manuscriptcentral.com/jamstuds. Authors who do not yet have an account on the online submission site will need to register before submitting a manuscript. If you are unsure about your login details or whether you have an account or not, please use the password help field on the login page. Do not create a new account if you are unsure.

If you experience any difficulties submitting your manuscript, please contact ScholarOne support at mchelp.manuscriptcentral.com/gethelpnow/question.htm
Any editorial correspondence should be addressed to the Co-Editors: Dr. Sinéad Moynihan and Dr. Nick Witham on the following email address: jas@baas.ac.uk

Submission of an article is taken to imply that it is an original work of scholarship and has therefore not previously been published, and has not been submitted for publication elsewhere. Authors of articles published in the journal assign copyright to Cambridge University Press and British Association of American Studies (with certain rights reserved) and will receive a copyright assignment form for signature on acceptance of your paper.

Contributors are responsible for obtaining permission to reproduce any material in which they do not own copyright, to be used in both print and electronic media and as regards images rights and high resolution files, and for ensuring that the appropriate acknowledgements are included in their manuscript.

\section{Manuscript preparation}

Articles should not exceed 8,000 words (excluding footnotes) OR 12,000 words (including footnotes).

Manuscripts should be submitted via the online submission system at mc.manuscriptcentral.com/jamstuds. Authors should remove their name from the manuscript and should ensure that their manuscript is fully anonymised. Authors should make sure that any tracked changes on the file have been removed.

File names should be of the type AMSauthorsurname. doc or .rtf for ease of identification. Diagrams, maps, and illustrations should be made into an eps file or a tif file and the file name should be AMSauthorsurname1.eps or .tif (where the number is the figure number) - please refer to cambridge.org/core/journals/journal-of-americanstudies/information/instructions-contributors for further information regarding technical specifications. If you request colour figures in the printed version, you will be contacted by CCC-RightsLink who acts on our behalf to collect author charges. Please follow CCC-RightsLink's instructions in order to avoid any delay in the publication of your article.

Contributors should keep one copy of the typescript for correcting proofs.

Open Access Policies: Please visit cambridge.org/openaccess for information on our open access policies, compliance with major finding bodies, and guidelines on depositing your manuscript in an institutional repository.

\section{Text preparation}

Authors should refer to the detailed instructions provided at cambridge.org/core/journals/journal-of-american-studies/ information/instructions-contributors before submitting their work.

Printed in the UK by Bell \& Bain Ltd

This journal issue has been printed on FSC-certified paper and cover board. FSC is an independent, non-governmental, not-for-profit organization established to promote the responsible management of the world's forests. Please see fsc.org for information. 


\section{JOURNAL OF AMERICAN STUDIES}

\section{VOLUME 55 ISSUE 2 MAY 2021}

\section{FORUM: PERCEIVING SECURITY AND INSECURITY: THE CAMPUS CARRY}

LAW IN TEXAS

243 Introduction: Perceiving Security and Insecurity: The Campus Carry Law in Texas Benita Heiskanen

252 Not in My Office: Rights in an Armed Campus Space Benita Heiskanen

262 Beyond Argumentum in Terrorem: The Contested Rhetoric of Campus Carry Albion M. Butters

274 "Like a Double-edged Sword": Student Testimonials on Campus Carry in Texas Malla Lehtonen and Mila Seppälä

286 Campus Carry and Active-Shooter-Event Emotion Management Juha Vuori

299 Not a "Nonissue": Perceptions and Realities of Campus Carry at The University of Texas at Austin Sampo Ruoppila and Albion M. Butters

\section{ARTICLES}

Imagined Hillarys: Feminism, Fantasy, and Fictional Clintons in The Good Wife and The Good Fight Rachel Sykes

336 Obamageddon: Fear, the Far Right, and the Rise of "Doomsday" Prepping in Obama's America Michael F. Mills

366 Patriots and Protesters, Mavericks and Manipulators: Assange, Snowden and the Politics of Surveillance Cinema lan Scott and Henry Thompson

387 "He Was Shot because America Will Not Give Up on Racism": Martin Luther King Jr. and the African American Civil Rights Movement in British Schools Megan Hunt, Benjamin Houston, Brian Ward and Nick Megoran

418 Rearing Children of the Market in the "You" Decade: Choose Your Own Adventure Books and the Ascent of Free Choice in 1980s America

\section{Eli Cook}

446 Restoring the State's Power to Defame: The Legal Life of Character in the Era of Roosevelt and Trump James B. Salazar

474 Space Occupied: Women Poet-Editors and the Mimeograph Revolution in Mid-century New York City Rona Cran

\section{REVIEW ESSAY}

502 Economies of Prestige and the Editorial Program Era: Literary Sociology and Tim Groenland's The Art of Editing Daniel Robert King

508 REVIEWS

ONLINE REVIEWS: cambridge.org/jams

\section{Cambridge Core}

For further information about this journal please go to the journal website at: 